\title{
Identification of biotransformation products of disperse dyes with rat liver microsomes by LC-MS/MS and theoretical studies with DNA: Structure-mutagenicity relationship using Salmonella/microsome assay
}

\author{
Jefferson Honorio Franco a, Bianca F. da Silva ${ }^{\text {a }}$, Regina V. Oliveira ${ }^{\mathrm{b}}$, Gabriela Meireles ${ }^{\mathrm{c}}$, \\ Danielle Palma de Oliveira ${ }^{\mathrm{c}, *}$, Alexandre A. de Castro ${ }^{\mathrm{d}}$, Teodorico C. Ramalho ${ }^{\mathrm{d}}$, Maria V.B. Zanoni ${ }^{\mathrm{a}}$ \\ a Institute of Chemistry-State University “Julio de Mesquita Filho"-UNESP-Avenida Professor Francisco Degni, 55, Quitandinha, 14800-900 Araraquara, SP, Brazil \\ ${ }^{\mathrm{b}}$ Federal University of São Carlos, UFSCar, Department of Chemistry, Rod. Washington Luiz Km 235, Monjolinho, 13565-905 São Carlos, SP, Brazil \\ ' School of Pharmaceutical Sciences of Ribeirão Preto, University of São Paulo - FCFRP/USP, Ribeirão Preto, São Paulo, Brazil \\ d Department of Chemistry, Federal University of Lavras, 37200-000 Lavras, Brazil
}

\section{H I G H L I G H T S}

- Biotransformation of azo dyes by rat liver microsomes

- Original textiles dyes and its degradation products may be harmful to the human health and environment.

- In vitro biotransformation experiments showed promising results for metabolism studies of azo molecules.

- Computational study and Ames test contributed to correlate dye's structure-mutagenicity relationship.

- LC-MS/MS technique has proved to be an important tool for characterization and identification of new compounds formed.

\section{A R T I C L E I N F O}

\section{Article history:}

Received 29 May 2017

Received in revised form 7 August 2017

Accepted 27 August 2017

Available online 22 September 2017

Editor: Kevin V. Thomas

\section{Keywords:}

In vitro biotransformation

Rat liver microsome

Mass spectrometry

Textile dye

Ames Test

Computational study

\footnotetext{
* Corresponding author.

E-mail address: dpalma@usp.br (D.P. de Oliveira).
}

\section{G R A P H I C A L A B S T R A C T}

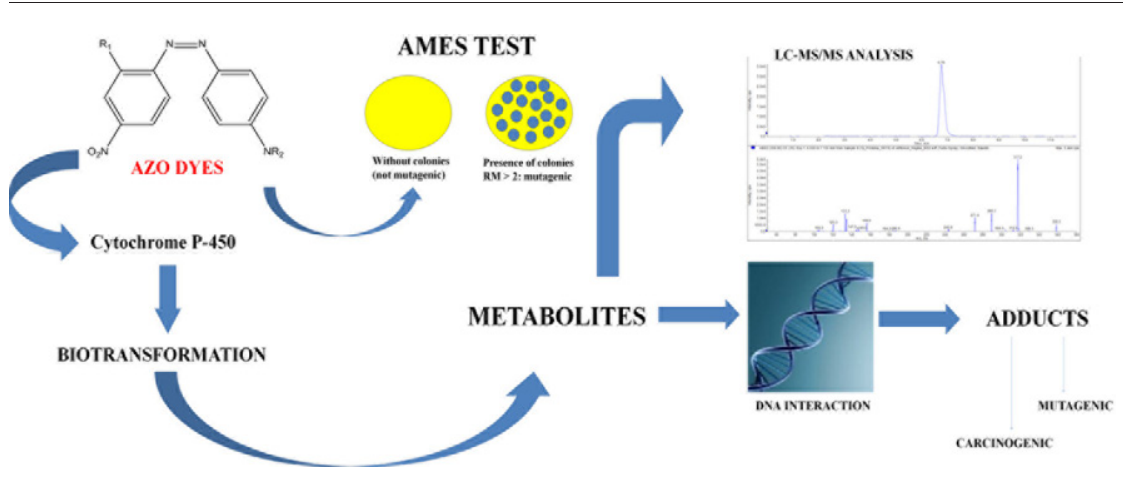

\section{A B S T R A C T}

Azo dyes are known as a group of substances with DNA damage potential that depend on the nature and number of azo groups connected to aromatic rings (benzene and naphthalene), chemical properties, e.g. solubility and reactive functional groups, which significantly affect their toxicological and ecological risks. In this paper, we used in vitro models to evaluate the metabolism of selected textile dyes: Disperse Red 73 (DR 73), Disperse Red 78 (DR 78) and Disperse Red 167 (DR 167). To evaluate the mutagenic potential of the textile dyes, the Salmonella mutagenicity assay (Ames test) with strains TA 98 and TA 100 in the presence and absence of the exogenous metabolic system (S9) was used. DR73 was considered the most mutagenic compound, inducing both replacement base pairs (TA 100) and also changing frameshift (TA 98) mutations that are reduced in the presence of the S9 mixture. Furthermore, we used rat liver microsomes in the same experimental conditions of the S9 mixture to metabolize the dyes and the resultant solutions were analyzed using a liquid chromatography coupled to a quadrupole linear ion trap mass spectrometry (LC-MS/MS) to investigate the metabolites formed by the in vitro biotransformation. Based on this experiment, we detected and identified two biotransformation products for each textile dye substrate analyzed. Furthermore, to evaluate the interaction and reactivity of these compounds with DNA, theoretical calculations were also carried out. The results showed that the chemical reaction occurred preferentially at the azo group and the nitro group, indicating that there was a reduction in these groups by the 
CYP P450 enzymes presented in the rat microsomal medium. Our results clearly demonstrated that the reduction of these dyes by biological systems is a great environmental concern due to increased genotoxicity for the body of living beings, especially for humans.

(c) 2017 Elsevier B.V. All rights reserved.

\section{Introduction}

Textile, cosmetics, tattooing, food and pharmaceutical industries worldwide utilize thousands of synthetic azo dyes in their formulations (Kolekar and Kodam, 2012). The ease and cost-effectiveness for synthesis, compared to natural dyes, is the major cause of the success of azo dyes, as well as the great structural diversity, high molar extinction coefficient, and high fastness properties in relation to light (Bafana et al., 2011). However, some azo dyes can show toxic effects, especially carcinogenic and mutagenic events (Chung and Cerniglia, 1992). Due to this extensive industrial use, large amounts of dyestuff, which are usually unbound dye materials, are directly discarded into wastewater during textile processing (Gomare et al., 2008). It is estimated that over 10,000 different dyes and pigments are used industrially and over $7 \times 10^{5}$ tons of synthetic dyes are annually produced worldwide (Ogugbue and Sawidis, 2011). In the textile industry, up to 200,000 tons of these dyes are lost to effluents every year during dyeing and finishing, due to the inefficiency of the dyeing process (Ogugbue and Sawidis, 2011). Unfortunately, ineffective waste treatment in conventional wastewater treatment processes results in the persistence of the dyes in the environment, causing a decrease in light penetration and photosynthetic activity (Forgacs et al., 2004). In addition, the presence of very small amounts of dyes ( $<1 \mathrm{mg} / \mathrm{L}$ for some dyes) in the water and the effects caused by other pollutants in textile wastewater, seriously affects the transparency of water bodies such as rivers, lakes and rivers and the aesthetic quality, leading to damage to the aquatic environment (Banat et al., 1996).

These dyes and their degradation products when released into water, even at very low concentrations, could be toxic, inducing carcinogenic, mutagenic or teratogenic effects to various organisms, including aquatic organisms and humans. Toxicological risks of these compounds are closely related to biotransformation processes (Umbuzeiro et al., 2005b; Umbuzeiro et al., 2005a), considering that changes to their chemical structure induced by different biological reactions, such as reduction, oxidation, acetylation and chlorination reactions may produce harmful compounds to the environment and human health (Novotný et al., 2006).

The biotransformation process of a dye occurs as any other xenobiotic and it can affect all toxicological profiles, leading to detoxification and excretion, but also promoting its bioactivation. For this reason, studies related to the biotransformation of xenobiotics are of major concern in the early stages of assessing their risks. The biotransformation of xenobiotics occurs in multiple tissues and the liver is the most important organ (Matsuo et al., 2008).

Among the various enzymatic systems responsible for metabolic processes, the main azo dye biotransformation route involves cytochrome P450 monooxygenases (CYP P450). The CYP P450 enzymes belong to a superfamily of heme proteins that are present in all living organisms, mainly in the liver, and they are involved in the metabolism of a wide variety of chemical compounds (Livingstone, 1998; Kleinow et al., 1987).

Chequer et al. (Chequer et al., 2011) studied the products formed by the oxidation and reduction of the Disperse Red 1 by the reaction with cytochrome P450 isoenzymes using the methodologies of HPLC-DAD and GC-MS and evaluated the mutagenic potential of these products using two different methods: the Salmonella/microsome test with the strains TA 98 and YG 1041 in the absence of exogenous metabolic activation (S9) and the rat lymphoma assay (MLA). The work concluded that azo dye Disperse Red 1 can be metabolized by hepatic enzymes that generate mutagenic compounds, such as nitrobenzene, which is a mutagenic product and should be used with precaution.

According to Hunger (Hunger, 1994), the reduction of azo dyes can occur in the liver by CYP P450, yielding products with mutagenic properties. While the carcinogenesis process is very complex, it is well known that chemical carcinogens can convert a normal cell into a malignant cell after repeated exposure to mutagenic or carcinogenic substances. Inside the cell, carcinogens or their metabolic products can promote a series of effects including regulation and gene expression, DNA repair, cell differentiation or apoptosis. Therefore, it is highly important to study the possible degradation products formed by the biotransformation of azo dyes (Vineis and Pirastu, 1997).

Stiborova and co-authors studied (Stiborová et al., 1988) the biotransformation of the azo dye (Sudan I) by microsomal enzymes of rat livers using in vitro experiments. The formation of the benzenediazonium ion evolved by oxidative cleavage of the azo bound of Sudan I by microsomal enzymes was demonstrated. Therefore, the results suggest that the hydroxy derivative products are not the main carcinogenic products, but rather their by products, which are very reactive and react rapidly with nucleophiles present in the cells, causing a conversion to carcinogenic compounds, which link to the DNA (Beland and Kadlubar, 1990). Additional studies using Sudan III (Zanoni et al., 2013) demonstrated that aromatic amines are formed after oxidative reactions mediated by CYP isoenzymes by hepatic cells.

Martin and Kennely (Martin and Kennelly, 1981) analyzed the role of rat microsomal azo-reductases in the metabolism of representative azo dye compounds by using spectrophotometric UV-Vis methods to measure the generated amines. For dyes derived from benzidine or its congeners, Direct Black 38 was reduced to an appreciable extent. Additionally, the dyes were also tested for mutagenicity using Salmonella/ microsome assay and the results suggested that mammalian liver plays a minor or negligible role in the azo-reduction of dyes derived from benzidine or its congeners. It must also be noted that at least part of its mutagenic activity may be due to the release of the potent mutagen 1,2,4-triaminobenzene (Martin and Kennelly, 1981).

In more recent years, several models for studies are used to evaluate the toxicity of xenobiotics and, among them, we could highlight the S9 fractions of human or rat liver used in the Ames test (Brandon et al., 2003). Although some azo dyes do not tested positive for mutagenicity using the standard Ames plate assay (Prival et al., 1988), they may undergo a reduction by liver microsomal fractions (Zbaida and Levine, 1990) and after the biotransformation reaction, the products formed may be more mutagenic than the original compound. Therefore, the Salmonella mutagenicity assay/microsome (Ames test) can be successfully used for mutagenesis of xenobiotics analysis (Novotný et al., 2006).

The monitoring and evaluation of the mechanistic biodegradation of dyes helps identify the formation of harmful compounds to animals and humans. Thus, this work aims to monitor the main metabolites generated by the biotransformation of textile dyes, such as Disperse Red 73 (DR 73), Disperse Red 78 (DR 78) and Disperse Red 167 (DR 167) (Fig. 1) using in vitro systems and rat liver microsome and compare their mutagenicity with and without an exogenous metabolic system (S9 mixture). The biotransformation products obtained from the in vitro reactions mediated by CYP-P450 were evaluated by LC-MS/MS analysis. In order to elucidate the interaction and reactivity of these compounds with DNA, theoretical calculations have also been performed. The identified metabolites were reported for the first time and require further studies to evaluate their degradation and toxicity in aquatic and human environments. 
<smiles>CCN(CCC#N)c1ccc(/N=N\c2ccc([N+](=O)[O-])cc2C#N)cc1</smiles><smiles>CCN(CCC#N)c1ccc(/N=N\c2ccc([N+](=O)[O-])cc2Cl)cc1</smiles><smiles>CCOC(=O)Nc1ccc(/N=N\c2ccc([N+](=O)[O-])cc2Cl)c(NC(C)=O)c1</smiles>

\section{(III)}

Fig. 1. Structure of Disperse Red 73 (DR 73) (I), Disperse Red 78 (DR 78) (II) and 167 Disperse Red (DR 167) (III) dyes.

\section{Materials and Methods}

\subsection{Chemicals and materials}

The water was obtained from a Milli-Q system (Millipore, São Paulo, Brazil). Disperse Red 73 (DR 73), Disperse Red 78 (DR 78) and Disperse Red 167 (DR 167) were obtained from Classic Dyestuffs Inc. (High Point, NC, USA). Methanol and acetonitrile (HPLC grade) were purchased from JT Baker (Center Valley, PA, USA).

The reagents potassium phosphate monobasic $\left(\mathrm{KH}_{2} \mathrm{PO}_{4}\right)$, sodium chloride, sodium phosphate, magnesium chloride, $\beta$-nicotinamide adenine dinucleotide phosphate and a reduced form (NADPH) were purchased from Sigma-Aldrich (St. Louis, MO, USA). All other reagents were of analytical grade.

\subsection{Microsomal Preparations}

Rat liver microsomes (RLM) were prepared by differential highspeed centrifugation using Wistar rats according to Belaz \& Oliveira (Belaz and Oliveira, 2013). Protein concentrations were determined by the Bradford method (Bradford, 1976). The microsomal preparations were stored at $-80{ }^{\circ} \mathrm{C}$ until analysis.

\subsection{Factorial Design $2^{4}$}

In vitro biotransformation experiments using textile dyes and rat liver microsomes were optimized using fractional factorial design $2^{4}$ and sixteen experiments were carried out randomly. In this experiment, four variables were investigated. These variables were assessed at two levels, a lower level and a higher level as described in Table S1 dye concentration ( 2 and $5 \mu \mathrm{g} \mathrm{mL} \mathrm{m}^{-1}$ ); protein concentration (10 and $\left.50 \mathrm{mg} \mathrm{mL}^{-1}\right)$; NADPH concentration ( 2 and $10 \mathrm{mmol} \mathrm{L}^{-1}$ ), and incubation time (60 and $120 \mathrm{~min}$ ). The optimal experimental conditions for the in vitro metabolism of textile dyes were as follows: $10 \mu \mathrm{L}$ of textile dye $\left(5 \mu \mathrm{g} \mathrm{L}^{-1}\right), 50 \mu \mathrm{L}$ of rat liver microsome ( $\left.50 \mathrm{mg} \mathrm{mL}^{-1}\right), 10 \mu \mathrm{L}$ NADPH $\left(5 \mathrm{mmol} \mathrm{L}^{-1}\right)$ and $430 \mu \mathrm{L}$ potassium phosphate buffer (100 $\mathrm{mmol} \mathrm{L}^{-1} ; \mathrm{pH} 7.0$ ) and $120 \mathrm{~min}$ for the reaction time.

For all experiments, the type and buffer concentration (phosphate buffer; $10 \mathrm{mmol} \mathrm{L}^{-1}$; pH 7.0) was kept constant. A total of 16 biotransformation experiments were conducted with all possible combinations of the selected levels of the variables. A higher production of potential metabolites for the in vitro metabolism of the dyes occurred when longer biotransformation time and higher protein concentrations were used.

\subsection{In vitro metabolism assay}

The in vitro metabolism experiments were carried out in Eppendorf tubes $(2 \mathrm{~mL})$, which contained $430 \mu \mathrm{L}$ of potassium phosphate monobasic buffer $\left(10 \mathrm{mmol} \mathrm{L}^{-1} ; \mathrm{pH} 7.4\right), 50 \mu \mathrm{L}$ microsomal fraction $\left(5 \mathrm{mg} \mathrm{mL}^{-1}\right)$ and $10 \mu \mathrm{L}$ dye solution $\left(5 \mu \mathrm{g} \mathrm{mL}^{-1}\right)$ prepared in acetonitrile. After pre-incubation of $5 \mathrm{~min}$ at $37^{\circ} \mathrm{C}$ in a shaking water bath, the reaction was started by adding $10 \mu \mathrm{L}$ of NADPH $\left(5 \mathrm{mmol} \mathrm{L}^{-1}\right)$, and the mixture was left stirring at a constant temperature of $37^{\circ} \mathrm{C}$ for the time of each experiment. The total incubation volume was $500 \mu \mathrm{L}$. The reaction was stopped by adding $500 \mu \mathrm{L}$ of cold acetonitrile. The mixture was left to stand in an ice bath for $5 \mathrm{~min}$ and then centrifuged at 10,000 $\times g$ for $15 \mathrm{~min}$. A volume of $200 \mu \mathrm{L}$ from the supernatant was collected and diluted with $100 \mu \mathrm{L}$ of water. A volume of $10 \mu \mathrm{L}$ was analyzed by LC-MS/MS. Negative controls were prepared: including: a) phosphate buffer with microsome; b) phosphate buffer with microsome and NADPH; c) phosphate buffer containing substrate (disperse dye), and d) phosphate buffer with NADPH. The percentage of biotransformation was calculated comparing the area of the biotransformation sample with those areas of the negative controls.

\subsection{Mutagenicity test with Salmonella typhimurium}

The Salmonella/microsome mutagenicity assay was performed with the TA 98 and TA 100 strains, as described by Maron and Ames (Maron and Ames, 1983) and Mortelmans and Zeiger (Mortelmans and Zeiger, 2000). The assays were conducted using the preincubation protocol in the presence and absence of exogenous metabolic system, using S9 mix containing 4\% (v/v) lyophilized aroclor-1254 induced rat liver S9 fraction (Moltox Inc.) and NADP as a cofactor.

Briefly: $100 \mu \mathrm{L}$ overnight cultures of Salmonella, $500 \mu \mathrm{L}$ of S9 mixture and $100 \mu \mathrm{L}$ of dye solution were placed into glass tubes and incubated at $37^{\circ} \mathrm{C}$ for $30 \mathrm{~min}$. After incubation, $2 \mathrm{~mL}$ of top agar was added to each tube, which was then transferred to plates containing minimal agar. The plates were incubated at $37^{\circ} \mathrm{C}$ for $66 \mathrm{~h}$ in the inverted position. The positive controls were 2 -aminoanthracene $\left(0.25 \mu \mathrm{g} \mu \mathrm{L}^{-1}\right)$ and 4nitroquinoline oxide $\left(0.05 \mu \mathrm{g} \mu \mathrm{L}^{-1}\right)$ for the assays with and without S9 mixture, respectively, and the negative control was dimethyl sulfoxide $(100 \mu \mathrm{L})$, DMSO, for all the tested conditions. The colonies were counted by hand and the background was carefully evaluated. The frequency of reverse mutation is easily measured by counting colonies growing on minimal media after the exposure of a population of cells to a mutagen.

The results were expressed as the mean number of revertants per plate \pm SD and as the mutagenic potency when the samples were positive. The mutagenic potency was obtained from the slope of the graph by using the Salanal software. This software uses the Bernstein model (Bernstein et al., 1982), which in turn uses ANOVA and linear regression analysis of the data.

\section{6. $L C-M S / M S$ experimental conditions}

LC-MS/MS experiments were carried out using the 1200 Agilent Technologies HPLC (Palo Alto, CA, USA) coupled to a 3200 QTRAP mass spectrometer (Linear Ion Trap Quadrupole Mass Spectrometer, AB SCIEX (Framingham, MA, USA) operating in positive ion mode with a Turbolon Spray ionization source. Chromatographic analyses were performed using a Luna C18 column (2) $(250 \mathrm{~mm} \times 4.6 \mathrm{~mm} ; 5$ $\mu \mathrm{m})$ and a mixture of water and acetonitrile $(20: 80, v / v)$ both containing $0.1 \%$ formic acid in isocratic mode at $1 \mathrm{~mL} \mathrm{~min}^{-1}$. The injection volume and temperature of the column were $10 \mu \mathrm{L}$ and $25^{\circ} \mathrm{C}$, respectively. 
The total analysis time was $10 \mathrm{~min}$. All measurements were performed in triplicate $(n=3)$.

MS data acquisition was performed in full scan mode (EMS, enhanced mass scan - using the linear ion trap mass analyzer). The ionization parameters for each dye were optimized on the mass spectrometer via direct infusion experiments of each individual standard $\left(20 \mu \mathrm{g} \mathrm{mL} \mathrm{L}^{-1}\right)$ prepared in methanol: water $(1: 1 ; \mathrm{v} / \mathrm{v})$ containing $0.1 \%$ formic acid at a flow rate of $10 \mu \mathrm{L} \mathrm{min}{ }^{-1}$.

The QTRAP was operated under the following conditions: capillary potential $5500 \mathrm{~V}$, dry gas temperature $550{ }^{\circ} \mathrm{C}$, Gas $150 \mathrm{psi}$, Gas 250 psi and curtain gas 15 psi. Declustering potential (DP) and entrance potential (EP) were specific for each dye and the values used were $36 \mathrm{~V}$ and $8.0 \mathrm{~V}$ for DR 73, $43 \mathrm{~V}$ and $5.0 \mathrm{~V}$ for DR 78 and $60 \mathrm{~V}$ and $8.0 \mathrm{~V}$ for DR 167, respectively. Fragment ion experiments (EPI, enhanced product ion) were conducted for additional structural information of the possible products formed during the biotransformation assay. The collision energy for these experiments ranged from 20-50 V.

\subsection{Computational methods}

\subsubsection{Quantum and semi-empirical calculations}

QM methods allow the modeling of electronic processes involved in the breaking and formation of chemical bonds, the transfer of charge and electron excitation. (Ryde, 2016; Senn and Thiel, 2009)

Considering this, Density Functional Theory (DFT) techniques have been widespread, showing good performance for complex systems, such as biomolecules (Besler et al., 1990; Singh and Kollman, 1984). The calculations were based on the generalized gradient approximation functional proposed by Gustin et al (Gustin et al., 1999). This relationship between density functional and the basis set has been tested for similar systems (da Cunha et al., 2010).

Dyes and their metabolites were fully optimized at the DFT level (Sost and Amrhein, 1990), with conjugate gradient and quasiNewton-Raphson algorithms. The final geometries were obtained with the density functional Becke's three-parameter exchange functional and the gradient-corrected functional proposed by Lee, Yang and Paar (B3LYP) (da Cunha et al., 2008), using 6-31 g (d,p) basis set.

To perform the calculations, the DICKERSON-DREW B-DNA DODECAMER was obtained from the Protein Data Bank (PDB) with code 4C64 and resolution: $1.32 \AA$ (Lercher et al., 2014). This DNA structure was chosen as the model according to previous studies (Haris et al., 2015; Issar et al., 2015). As mentioned previously, the dyes and their metabolites were entirely optimized at DFT level for the subsequent PM6 semi-empirical calculations with BDNA. The DFT method is also appropriate to perform the Natural Bond Orbital (NBO) analyses and the reaction mechanism calculations (Silva et al., 2017). After full optimization of the DNA-dye systems at the PM6 level, a semi-empirical method, NBO calculations were also carried out (Silva et al., 2017; Foster and Weinhold, 1980). In addition, a theoretical investigation considering the reaction mechanism of these dyes with DNA was performed to evaluate the electronic and steric effects on the thermodynamic properties of this process.

Regarding the semi-empirical calculations, which emerged in 1931 from Michael Polanyl and Henry Eyring (Morgon and Coutinho, 2007), who addressed the quantum theory coupled to empirical results, producing satisfactory data (Morgon and Coutinho, 2007). Therefore, optimization calculations were carried out for all systems to obtain the interaction energy. The application of these methods is crucial to gain a better understanding with respect to interaction and reactivity of these dyes with DNA, which can also reveal molecular aspects that contribute to the mutagenic potential.

\section{Results and Discussion}

3.1. In vitro biotransformation of textile dyes DR 73, DR 78 and DR 167 using rat liver microsomes

Comparing the full MS scan of the control sample with the rat liver microsomes, the DR 73 and DR 167 samples depleted $100 \%$ from their initial concentrations, while for the DR 78 substrate; a depletion area of $69 \%$ was observed. The LC-MS/MS chromatographic profile obtained for DR 73, DR 78 and DR 167 standard dye $\left(20 \mu \mathrm{gL}^{-1}\right)$ in EMS mode showed the elution of DR 73 dye at $4.62 \mathrm{~min}$ as $\mathrm{m} / \mathrm{z} 349$, which corresponded to the protonated molecule, $[\mathrm{M}+\mathrm{H}]^{+}$(Fig. S1a) and its fragmentation pattern (Fig. S1b). Furthermore, DR 78 dye was detected in $6.76 \mathrm{~min}$ as $\mathrm{m} / \mathrm{z} 359\left([\mathrm{M}+\mathrm{H}]^{+}\right.$) (Fig. S2a, fragmentation pattern S2b) and DR 167 dye was detected at $6.20 \mathrm{~min}$ as $\mathrm{m} / z 506\left([\mathrm{M}+\mathrm{H}]^{+}\right.$ (Fig. S3a, fragmentation pattern S3b).

Because the total ion chromatogram covers a wide mass range and shows a high background that undermines the visual detection of new peaks on the chromatogram, the approach of using background subtraction was adopted for all sample analyses.

It is important to note that all other chromatographic peaks detected in the extracted ion chromatograms, with the exception of the chromatographic peak of the biotransformation product, refer to components of the reaction medium and were detected in the control samples. Thus, the MS/MS mass spectrum was performed to confirm that the chromatographic peaks of interest were new metabolites formed.

During the in vitro studies of DR 73, by comparing the chromatograms obtained for biotransformation and control samples, a potential metabolite (1) with $m / z 319\left([\mathrm{M}+\mathrm{H}]^{+}\right)$was observed at $3.41 \mathrm{~min}$, indicating the presence of a metabolite obtained by a chemical reduction in the nitro group, $\left(-\mathrm{NO}_{2}\right)$ to $\mathrm{NH}_{2}$. This product was further confirmed by analyzing the extracted ion chromatogram and fragment ions (EPI) of $m / z 319$ (Fig. S4(a-b)). The fragment ion mass spectrum showed $\mathrm{m} / \mathrm{z} 278$ as the base peak that corresponds to the loss of a methyl cyanide (41 Da). Another fragment ion observed was $m / z 221$, indicating the loss of the disubstituted amine, which was bound to the aromatic ring. Therefore, this new metabolite (1) was attributed to 2-(2-(4-((2cyanoethyl)(ethyl)amino)phenyl)hydrazinyl)-5-nitrobenzonitrile as the main product after the biotransformation of DR 73 dye. A fragmentation proposal could be outlined from the LC-MS/MS experiments, as shown in Scheme 1. These results showed that the DR 73 dye is metabolized by CYP P450 enzymes in the rat liver microsome, producing a major metabolite with $m / z 319$, which occurs by reducing the nitro dye group.

In addition to the metabolite (1), another chromatographic peak from the biotransformation of DR 73 was also detected, which was not observed in any of the control samples. This peak was detected at $3.09 \mathrm{~min}$ and showed $\mathrm{m} / \mathrm{z} 351[\mathrm{M}+\mathrm{H}]^{+}$(Fig. S5(a)). The mass difference of $2 \mathrm{Da}$ indicated a reduction which is associated to the reduction of the azo group resulting in a hydrazo group. The presence of this potential metabolite (2) was confirmed by MS/MS analysis of $m / z 351$ (Fig. S5(b)). The MS/MS mass spectrum showed a fragment ion $\mathrm{m} / \mathrm{z}$ 310 , which relates to the loss of a methyl cyanide (41 Da). Another fragment ion observed at $m / z 281$ is related to the loss of the nitro group and the cyanide attached to the aromatic ring. Based on the fragment ion spectrum obtained (Fig. S5(b)), the metabolite (2) was attributed to 5-amino-2-((4- $((2-$

cyanoethyl)(ethyl)amino)phenyl)diazenyl)benzonitrile. Scheme 2 illustrates the fragmentation proposal for this new metabolite. Thus, we can conclude that the in vitro biotransformation of the DR 73 produced two biotransformation products that were obtained by reducing the azo and nitro groups of the dye molecule, respectively.

Investigations into the possible metabolites formed from DR 78 were performed and careful analysis of the biotransformation sample demonstrated the presence of a peak $m / z 328\left([\mathrm{M}+\mathrm{H}]^{+}\right)$at 3.86 min and 


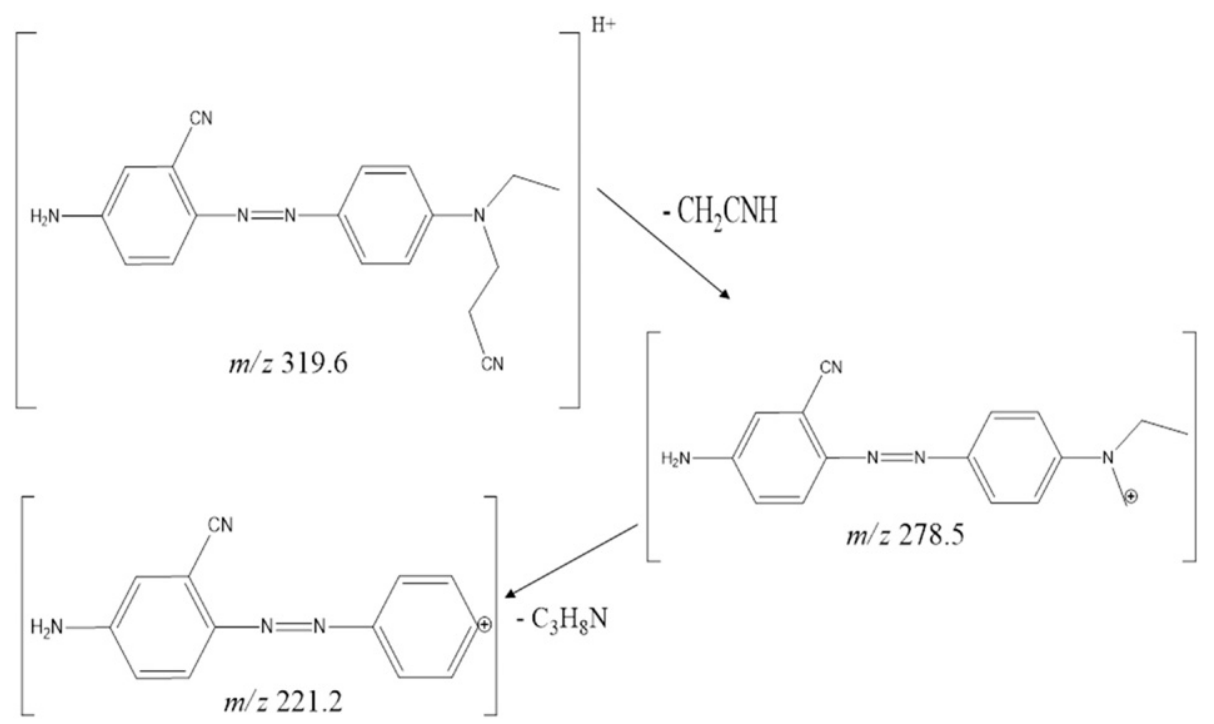

Scheme 1. Fragmentation proposal for the metabolite (1) $\mathrm{m} / z 319$, formed after incubation of $20 \mu \mathrm{mL} \mathrm{L}^{-1}$ of DR 73 standard dye with rat liver microsome.

the mass difference of 30 Da to the molecular ion showed a chemical reduction in the nitro group, $\left(-\mathrm{NO}_{2}\right)$ to $\mathrm{NH}_{2}$. The potential product was further confirmed by analysis of fragment ions (EPI) of $m / z 328$ (Fig. S6(a)). The fragment ion mass spectrum (Fig. S6(b)) showed $\mathrm{m} / \mathrm{z} 287$ that corresponds to the loss of a methyl cyanide (41 Da). Another fragment ion observed was $m / z 259$, indicating the loss of one ethyl group. Additionally, the ion $m / z 126$ was also observed and it correlates to the cleavage of the amine bond linked to the azo group, which is linked to the chlorinated aromatic ring. Therefore, this new metabolite (3) was attributed to 3-((4-((4-amino-2chlorophenyl)diazenyl)phenyl)(ethyl)amino)propanenitrile as the main product after the biotransformation of DR 78 dye. A fragmentation proposal was outlined for the LC-MS/MS experiments, as shown in Scheme 3. These results showed that the DR 78 dye is metabolized by CYP P450 enzymes in the rat liver microsome, producing a major metabolite with $m / z 328$, which occurs by reducing the nitro dye group.

The metabolite (3) obtained $(\mathrm{m} / \mathrm{z} 328)$ for the DR 78 was detected at $3.86 \mathrm{~min}$ and formed by the same reduction reaction of the nitro group observed for the production of the metabolite (1) for the DR 73, which obtained the product of $m / z 319$. However, although the DR 73 and DR 78 dyes had similar chemical structures, the metabolism of DR 78 dye did not produce a metabolite with a reduction of the azo group, as was observed for the DR 73 dye.

For the biotransformation of the dye DR 167, a product was detected at $4.56 \mathrm{~min}, \mathrm{~m} / \mathrm{z} 508\left([\mathrm{M}+\mathrm{H}]^{+}\right)$indicating the formation of a potential new metabolite (4). The mass difference of 2 Da compared to the substrate $(\mathrm{m} / z 506)$ indicated a reduction, which was again associated to the reduction of the azo group resulting in the hydrazo group of this ion. The presence of this potential metabolite was confirmed by extracted ion chromatogram and MS/MS analysis of $m / z 508$ (Fig. S7(a-b)). To propose a chemical structure of the detected product, initially an analysis of MS/MS of $m / z 508$ (Fig. S7(b)) was attempted and regardless of the fragmentation energy used, the ion $\mathrm{m} / \mathrm{z} 508$ showed no fragment ions and, therefore, it was not possible to obtain a fragmentation pattern.

To overcome this, the ion was confirmed by extracted ion spectrum was identified as dimethyl 3,3'-((3-acetamido-4-(2-(2chloro-4-nitrophenyl)hydrazinyl)phenyl)azanediyl)dipropanoate (metabolite 4).

Moreover, an additional chromatographic peak was also detected from the biotransformation of DR 167 at $4.21 \mathrm{~min}$ and showed $\mathrm{m} / \mathrm{z}$ $435[\mathrm{M}+\mathrm{H}]^{+}$(Fig. S8(a)), which was not detected in any of the control samples. This product was further confirmed by analysis of fragment

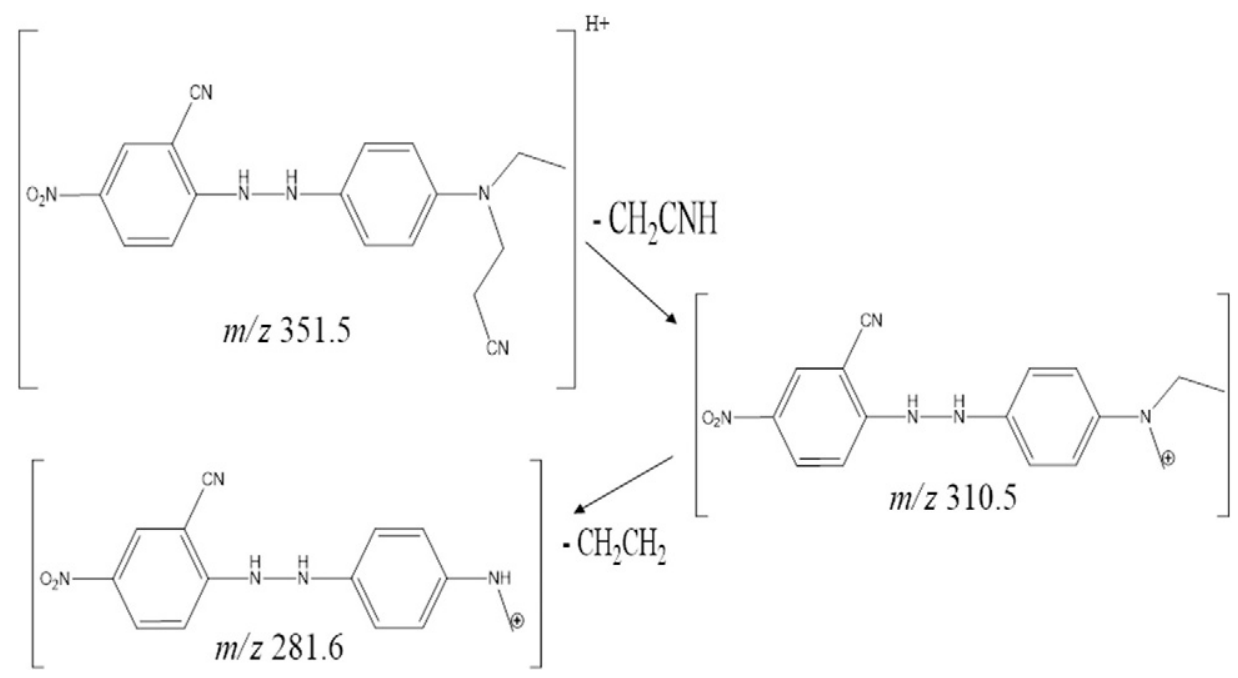

Scheme 2. Fragmentation proposal for the metabolite (2) $\mathrm{m} / z$ 351, formed after incubation of $20 \mu \mathrm{gL} \mathrm{L}^{-1}$ of DR 73 standard dye with rat liver microsome. 


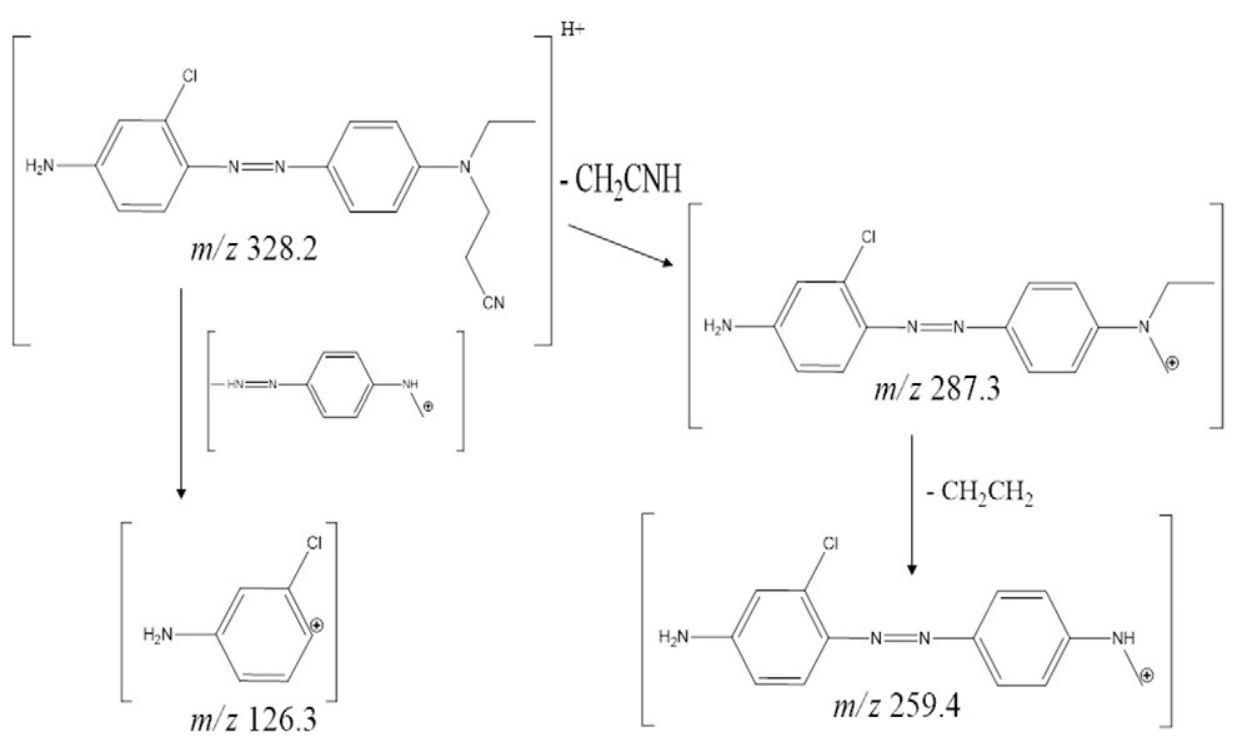

Scheme 3. Fragmentation proposal for the metabolite (3) $\mathrm{m} / \mathrm{z} 328$, formed after incubation of $20 \mu \mathrm{g} \mathrm{L}^{-1}$ of DR 78 standard dye with rat liver microsome.

ions (EPI) of $m / z 435$ (Fig. S8(b)). The fragment ion mass spectrum at $m /$ $z 337$ (base peak) corresponds to the loss of a methanol (32 Da), methyl aldehyde (30 Da) and chloride (35.5) from the substrate $(\mathrm{m} / z 506)$. Therefore, this new metabolite (5) was attributed to 3,3'-((4-((2chloro-4-hydroxyphenyl)diazenyl)phenyl)azanediyl)dipropanoate acid. A fragmentation pattern proposal was outlined for the LC-MS/MS experiments, as shown in Scheme 4.

Analyzing the obtained metabolite $(5)(\mathrm{m} / \mathrm{z} 435)$ after biotransformation of DR 167, we can concluded that there was a reduction of the amide to amine group, besides the loss of the nitro group attached to the aromatic ring, with subsequent addition of a hydroxyl group. Whereas the rat microsome acted preferably in the azo and nitro bond of DR 73 dye, and in the nitro bond of the DR 78 dye, there was a different actuation of the protein in the DR 167 dye. Consequently, there was a reduction in the amide group and a loss of the nitro group $\left(\mathrm{NO}_{2}\right)$ with a further addition of a hydroxyl to the aromatic ring. These changes in the molecule structure, probably occurred due to the structure of DR 167 dye, which is quite different compared to the other two dyes: DR 73 and DR 78.
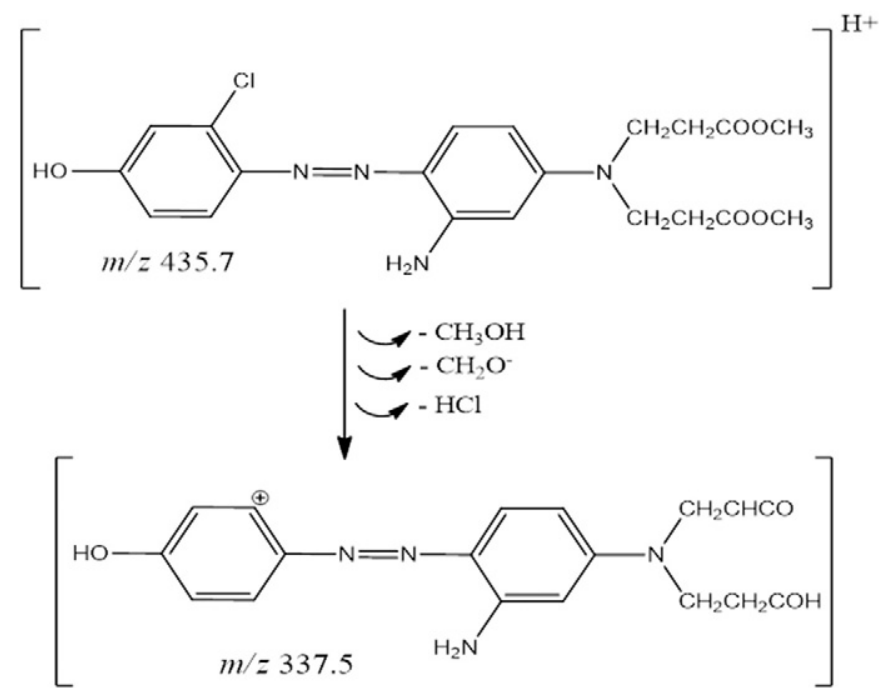

Scheme 4. Fragmentation proposal for the metabolite (5) $m / z 435$, formed after incubation of $20 \mu \mathrm{g} \mathrm{mL}^{-1}$ of DR 167 standard dye with rat liver microsome.
Table 1 summarized the products obtained for each disperse dye after a reaction with rat liver microsomes and their identification by LC-MS/MS.

\subsection{Mutagenicity evaluation of $D R 73, D R 78$ and $D R 167$}

The Salmonella/microsome assay is the most used in Environmental Mutagenesis research (Claxton, 1983), which uses specific bacterial strains to diagnose the nature of the mutagenic molecular action. Using this technique, it is also possible to estimate the indirect genotoxic effects on higher organisms by using fraction of P-450 liver metabolism of rats in vitro.

The Salmonella/microsoma assay was adopted using Salmonella typhimurium, histidine auxotrophic (histidine-dependent) strains, unable to grow in minimal medium, unless mutations occur that restore the synthesis of this amino acid. Many strains were constructed to detect several types of reverse mutations, such as base pair substitution (TA100) and error in the reading frame (TA98) of DNA (Pagano and Zeiger, 1992).

In order to evaluate the potential mutagenic activity of the formed compounds, we used the Salmonella mutagenicity assay (Ames test) in the presence and absence of the S9 mixture to simulate the biotransformation mediated by CYP isoenzymes. We also compared the results using the same protocol in the absence of exogenous metabolic activation.

Table 2 shows the mutagenic potential of the dyes using the strains TA 98 and TA 100, with and without metabolic activation. The results for each dye with Salmonella mutagenicity assay/microsome are shown in the supplementary material (Tables S2-S4).

Our results showed that Disperse Red 73 is the most mutagenic compound, exhibiting a mutagenic potential of $30 \mathrm{rev} / \mu \mathrm{g}$, with the strain TA 98 , in the absence of metabolism ( - S9). This compound can be considered as a moderate mutagen, based on the classification proposed by

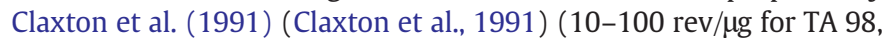
without S9). The biotransformation of DR 73 by CYP isoenzymes reduces around 6 time the mutagenicity of the original compound for TA 98 ( 5 rev/ug - Table 2). For TA 100 strain, the mutagenicity is around $34 \mathrm{rev} / \mu \mathrm{g}$ in the absence of $\mathrm{S} 9$ mixture, also reduced after the metabolic activation with 59 (Table 2). Therefore, this compound can induce base pair substitution and frameshift mutations, detected by TA 100 and TA 98 , respectively, revealing a direct toxic effect, but also an indirect action (detected by the presence of S9), even if in smaller number revertants in the presence of the $S 9$ mixture. 
Table 1

Biotransformation products of Disperse Red 73 (DR 73), Disperse Red 78 (DR 78) and Disperse Red 167 (DR 167) dyes.

\begin{tabular}{|c|c|c|c|}
\hline & Dyes Metabolites & $m / z$ & $\begin{array}{l}\text { Retention time } \\
\text { (min) }\end{array}$ \\
\hline DR 73 dye & & 349.5 & 4.62 \\
\hline
\end{tabular}

DR 73 biotransformation product

DR 73 biotransformation product

5-amino-2-((4-((2-cyanoethyl)(ethyl) amino) phenyl)diazenyl)benzonitrile<smiles>CCN(CCC#N)c1ccc(NNc2ccc([N+](=O)[O-])cc2C#N)cc1</smiles>

DR 78 dye

2-(2-(4-((2-cyanoethyl)(ethyl)amino) phenyl) hydrazinyl)-5-nitrobenzonitrile<smiles>CCN(CCN)c1ccc(/N=N/c2ccc([N+](=O)[O-])cc2Cl)cc1</smiles>

DR 78 biotransformation product<smiles>CCN(CCO)c1ccc(/N=N/c2ccc(N)cc2Cl)cc1</smiles>

DR 167 dye

3-((4-((4-amino-2-chlorophenyl)diazenyl) phenyl)(ethyl)amino)propanenitrile<smiles>COCCN(CCOC)c1ccc(N=Nc2ccc([N+](=O)[O-])cc2Cl)c(NC(C)=O)c1</smiles>

DR 167 biotransformation product<smiles>COCCN(CCOC)c1ccc(NNc2ccc([N+](=O)[O-])cc2Cl)c(NC(C)=O)c1</smiles>

DR 167 biotransformation product

Dimethyl 3,3'-((3-acetamido-4-(2-(2-chloro-4-nitrophenyl)hydrazinyl)phenyl)azanediyl)dipropanoate<smiles>COCCN(CC(C)=O)c1ccc(/N=N/c2ccc(O)cc2Cl)c(N)c1</smiles> 
The Disperse Red 78 and Disperse Red 167 can be considered as extremely low mutagenic compounds, also based on Claxton et al. (1991) classification, because their mutagenic potential are between 0.1 and $1 \mathrm{rev} / \mu \mathrm{g}$, for TA 98 , without S9 (Table 2). Our results corroborate with the literature, showing that the nature and position of the substituents linked to the azo bound are crucial for the toxic observed effect, Chung and Cerniglia, 1992; Umbuzeiro et al., 2005b). After the metabolic activation, we observed an increase in the mutagenic potential of both DR 78 and DR 167, although the response is still very weak. In the experiments with TA 100, both dyes tested negative (Table 2).

Taken together, the results demonstrated that DR 73, DR 78 and DR 167 induced higher mutagenic activity for TA 98 when compared to the TA 100 strain. However, only DR 73 induced to significant responses after the metabolic activation, possibly because the products generated after via cytochrome P-450 metabolism had low mutagenic activity (Saratale et al., 2011; Oliveira et al., 2007).

Concern about the carcinogenic risk of azo dyes and their degradation products began with the study published by Rehn (1985) as cited in Dipple et al., who observed that workers from an aniline dye factory in Germany developed urinary bladder cancer. This fact prompted the subsequent animal testing of various chemicals to which these workers were exposed, and the consequent discovery of carcinogenic activity of the azo dye 20,3-dimethyl-4-aminoazobenzene for the liver of rats and mice (Dipple et al., 1985).

Azo dyes can be ingested by humans and other living beings through the consumption of contaminated water or food, and they can undergo oxidation or reduction processes in the body, with the consequent generation of products more or less toxic than the original molecules (Chung, 1983; Umbuzeiro et al., 2005b).

CYP-450 enzymes play an important role in oxidative biotransformation reactions of xenobiotics. Studying the biotransformation of Sudan III, Zanoni et al. (2013) verify that oxidative reactions catalyzed by CYP-450 generated aromatic amines that increase the mutagenic effect of the original compound. In contrast, our study showed that the biotransformation of DR 73, DR 78 and DR 167 reduces their toxicity, observing the reduction on mutagenic potential of the dyes using the Ames test in the presence of S9 mixture (Zanoni et al., 2013).

A variety of azo compounds have been shown to act as substrates in reduction reactions by mammalian liver enzymes, suggesting that the fact of forming an amine is a pre-requisite for carcinogenicity (Zbaida and Levine, 1990; Decloitre et al., 1975). As previously described, in the present study, we performed an in vitro reduction biotransformation and the metabolites were monitored using LC-MS/MS.

We clearly showed that reduction reaction of the Disperse dyes also altered the nitro group, causing its reduction to $\mathrm{NH}_{2}$ in the DR 73 and DR 78 dyes, as well as the reduction of the azo bond, yielding the hydrazo group, in DR 73 and DR 167 dyes. The proposed chemical structures of the metabolites obtained in this study are still not reported in the literature regarding their risk as mutagenic or carcinogenic compounds. However, chemical groups presented in the structures of the metabolites detected are part of the classification proposed by the International Agency for Research on Cancer (IARC) (International Agency for Research on Cancer, 2002) and the most dangerous to human health,

\section{Table 2}

Mutagenic potential of the Disperse Red 73 (DR 73), Disperse Red 78 (DR 78) and Disperse Red 167 (DR 167) dyes, obtained in experiments with the strains Ta98 and TA100 in the absence and presence of exogenous metabolic system (S9 mixture), expressed in revertants/ $\mu \mathrm{g}(\mathrm{rev} / \mu \mathrm{g})$.

\begin{tabular}{|c|c|c|c|c|}
\hline \multirow[t]{3}{*}{ Compound } & \multicolumn{4}{|c|}{ 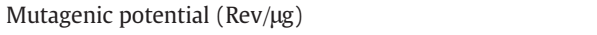 } \\
\hline & \multicolumn{2}{|l|}{ TA 98} & \multicolumn{2}{|l|}{ TA 100} \\
\hline & - S9 & $+S 9$ & $-S 9$ & $+S 9$ \\
\hline DR 73 & 29.94 & 5.04 & 34.44 & 1.02 \\
\hline DR 78 & 0.21 & 0.42 & - & - \\
\hline DR167 & 0.31 & 0.46 & - & - \\
\hline
\end{tabular}

either by ingestion or contact is benzonitrile which is classified as a possibly carcinogen for humans. This finding could explain the mutagenic response presented by DR73 in the absence of S9 mixture. Considering that Salmonella thyphimurium is an entero bacteria, reductive reactions are expected due to the expression of nitro and azoreductase enzymes in intestinal microflora (Maron and Ames, 1983; Chung and Cerniglia, 1992).

The chemical structure of each textile dye is of fundamental importance for the possible metabolites that can be formed, because a relevant property of environmental genotoxic mutagens is related to the high electrophilic character of the molecule or its derivative (Osugi et al., 2009). This property increases the possible reaction with DNA nucleophilic centers, leading to the formation of adducts. If this genotoxic effect is not repaired, it may promote the occurrence of permanent change in the DNA, leading to a mutagenic effect (Ferraz et al., 2011).

In this paper, DR 73 presented much higher values of revertants per plate as compared to DR 78 and DR 167. DR 73 contains a cyanide atom in its structure, whereas DR 78 bears chlorine as one of the aromatic ring substituents and DR 167 contains chlorine and a bulky disubstituted amine $\left(\mathrm{C}_{2} \mathrm{H}_{4} \mathrm{OCOCH}_{3}\right)$ group. The substituents in DR 78 and DR 167 probably decreased the electron density in the azo group, consequently diminishing their mutagenicity as compared to DR 73. These data corroborate with the study of Ferraz et al. (2011) that demonstrated that chlorine substitution greatly reduce the mutagenic potential of Disperse Red 13 when compared to Disperse Red 1 (Ferraz et al., 2011). According to Levine (1985), electron donating and the withdrawal of groups from the aromatic ring markedly affected the coupling reaction by way of inductive and resonance effects (Levine, 1985).

In order to prove our theory, a theoretical calculation study of the interaction of dye structures with DNA was performed.

\subsection{Computational results of intermolecular interaction, $N B O$ analyses and reaction mechanism calculations}

The azo compounds are characterized by the presence of one or more azo groups. They are known for presenting DNA damage potential (Mitra et al., 2007). These compounds are indeed involved in some biological reactions with DNA, due to their ability to form adducts (Mitra et al., 2007). In this line, the interaction energy for these compounds were evaluated by employing PM6 calculations, which consider the electronic effects that modulate their interaction modes with DNA. It should be kept in mind that the interaction energy can indicate a certain trend in relation to the experimental data, however, the relative activation energy ( $\Delta \Delta E^{\#}$ values in Table 4$)$ could, in principle, provide vital clues concerning the mutagenic potential.

The interaction energy for the DNA-dye system was evaluated by Eq. (1), where the energy of the free DNA and free dye systems were calculated.

$\mathrm{E}_{\text {int }}=\mathrm{E}_{\text {system }}-\left(\mathrm{E}_{\text {Dye }}+\mathrm{E}_{\mathrm{DNA}}\right)$

The theoretical findings are described in Table 3. By using this theoretical methodology, the affinity and interaction between disperse dyes and DNA could be evaluated, where these factors modulate the consequent reactivity. According to Table 3, our results indicate that Disperse Red 73 dye presented a significant affinity with DNA, with the smallest interaction energy in relation to the other dyes. Thus, the docking calculations show that DR 73 is more reactive, suggesting a higher mutagenic potential, that were demonstrated by our mutagenic results. This great interaction with the DNA structure can be due to the presence of cyanide groups attached to the compound. After the optimization calculations, it can be observed that the cyanide groups interacted strongly with the DNA structure (Fig. 2), which can help to explain their higher activity in relation to other dyes. DR 167 showed an energy value of $8.80 \mathrm{kcal} \cdot \mathrm{mol}^{-1}$ higher than DR 73. On the other hand, DR 78 showed 
Table 3

Relative interaction energy values from each dye and their metabolites in the DODECAMER B-DNA

\begin{tabular}{|c|c|c|}
\hline Dyes & Metabolites & $\operatorname{PM} 6 \Delta \Delta \mathrm{E}\left(\mathrm{kcal} \cdot \mathrm{mol}^{-1}\right)$ \\
\hline \multirow[t]{3}{*}{ Disperse Red 73} & & 0.00 \\
\hline & 5-amino-2-((4-((2-cyanoethyl)(ethyl)amino)phenyl)diazenyl)benzonitrile & 4.94 \\
\hline & 2-(2-(4-((2-cyanoethyl)(ethyl)amino) phenyl) hydrazinyl)-5-nitrobenzonitrile & 4.30 \\
\hline \multirow[t]{2}{*}{ Disperse Red 78} & & 12.40 \\
\hline & 3-((4-((4-amino-2-chlorophenyl)diazenyl) phenyl)(ethyl)amino)propanenitrile & 4.76 \\
\hline \multirow[t]{3}{*}{ Disperse Red 167} & & 8.80 \\
\hline & Dimethyl 3,3'-((3-acetamido-4-(2-(2-chloro-4-nitrophenyl)hydrazinyl)phenyl)azanediyl)dipropanoate & 15.73 \\
\hline & 3,3'-((3-amino-4-((2-chloro-4-nitrophenyl)diazenyl)phenyl)azanediyl)dipropanoic acid & 5.29 \\
\hline
\end{tabular}

a higher interaction energy value of $12.40 \mathrm{kcal} \cdot \mathrm{mol}^{-1}$. Based on these findings, the following descending order of interaction with DNA can be observed: Disperse Red $73>$ Disperse Red $167>$ Disperse Red 78, keeping in mind that dyes DR 78 and DR 167 presented similar energy values.

For each dye, the reactivity towards DNA was also tested for the metabolite compounds and the results are described in Table 3. According to these values, the DR 73 metabolites also interacted significantly toward DNA, presenting relative energy values between 4 and $5 \mathrm{kcal} \cdot \mathrm{mol}^{-1}$, keeping the reactivity level of DR 73 . The same trend is observed for the metabolite from DR 78, revealing that metabolites from DR 78 can be more reactive than the precursor dye. On the other hand, for DR 167, its metabolites presented larger oscillations of energy among them. After the optimization calculations, the NBO procedure was carried out

The NBO results, reported in Table 4, can be useful to evaluate electronic effects based on electron donating and electron accepting groups. The NBOs are orbitals located along the chemical bonds. Thus, atomic charges as well as intra- or intermolecular bonds can be described by means of the electronic density that involves atoms that participate in some kind of interaction (Foster and Weinhold, 1980).

In Table 4, it can be observed that the change of substituent ( $\mathrm{CN}$ to $\mathrm{Cl}$ ) plays an important role in the compound reactivity. According to the natural charge values, there is a formation of an electronic density on the cyanide group of DR 73, which could explain the significant interaction of this group with DNA. In DR 78, the change of substituent leads to a higher electronic density in the azo group, in relation to DR 73. It is important to keep in mind that the nitro group did not present significant changes. On the other hand, DR 167 showed charge differences considering the azo and nitro groups of 0.01163 a.u. and 0.03275 a.u., respectively. The chlorine substituent in DR 78 is found to be more electrophilic than in DR 167, with a charge difference of 0.02311 a.u.

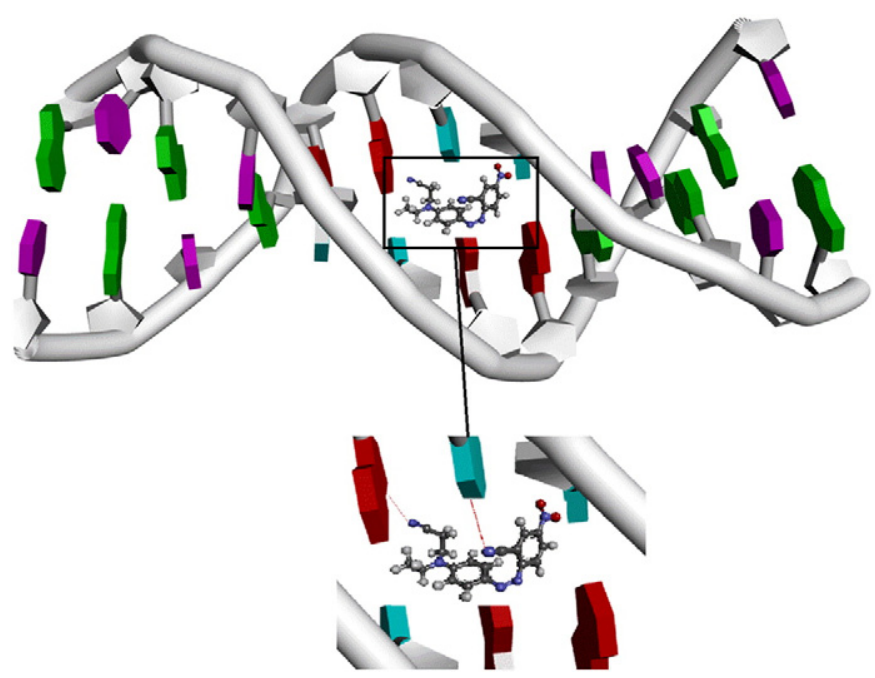

Fig. 2. Disperse Red 73/B-DNA DODECAMER system.
Differences concerning the natural charges between DR 78 and DR 167 can be related to structural changes in these compounds. In fact, DR 73 seems to have a less nucleophilic nitro group regarding the other dyes.

In case of contamination with dyes, the DNA may undergo damage due to their mutagenic potential. These alterations are very stable, and show a meaningful impact on the regulation of gene expression. According to previous studies, there are several possible reaction mechanisms between these compounds and DNA. Amongst these are the radical mediated $\mathrm{H}$-abstraction from the sugar moiety followed by oxidative cleavage. Another possibility, which is more likely for the studied compounds, is the alkylation mechanism of DNA bases (Luczak and Jagodzinski, 2006; Mitra et al., 2007). Accordingly, the reaction mechanism calculations for the alkylation process were performed considering the studied dyes (Fisher et al., 1992).

Our theoretical findings (Table 4) for the reaction mechanism of DR 73 , DR 78 and DR 167 with DNA corroborate with the experimental data of mutagenic potential (Table 2). It is noteworthy that the more reactive compound, DR 73, presented the lowest activation energy for the reaction to take place. Meanwhile, DR 167 had an intermediate energy and DR 78 presented the highest energetic barrier, with an energy difference of $10.27 \mathrm{kcal} \cdot \mathrm{mol}^{-1}$ in relation to DR 73 . In fact, mechanisms of the mutagenicity of azo dyes and their metabolites cannot be related only to the docking results. A more in-depth understanding of this phenomenon requires an interplay of both experimental and theoretical methodologies, such as docking calculations (Table 3 ) to evaluate the binding process, and the reaction mechanism calculations (Table 4) to investigate the reactivity of studied compounds with DNA. It is certainly worth noticing that both theoretical approaches are in good agreement with the experimental data (Table 2).

\section{Conclusion}

The system using rat liver microsome using NADPH as a cofactor was a viable approach to study the biotransformation reaction of textile dyes

\section{Table 4}

The Natural Bond Orbital analyses for the substituents of Disperse Red 73, Disperse Red 78 and Disperse Red 167 in DNA, and relative reaction mechanism results at B3LYP/6-31G (d, p) level of theory after optimization.

\begin{tabular}{llll}
\hline Dyes & Substituents & Total natural charge & $\Delta \Delta \mathrm{E}^{\#}\left(\mathrm{kcal} \cdot \mathrm{mol}^{-1}\right)$ \\
\hline Disperse Red 73 & & & \\
& CN & -0.01455 & 0.00 \\
& Azo & -0.27806 & \\
Nisperse Red 78 & Nitro & -0.25760 & \\
& Cl & 0.03590 & 10.27 \\
& Azo & -0.28969 & \\
Disperse Red 167 & Nitro & -0.25984 & \\
& & & \\
& Cl & 0.01279 & \\
& Azo & -0.24531 & \\
& Nitro & -0.29069 & \\
\hline
\end{tabular}

a All natural charge values are in a.u. 
as it allowed for the in vitro formation of new metabolites from the chemical reactions of DR 73, DR 78 and DR 167.

The LC-MS technique developed to evaluate the formation of biotransformation products in vitro has proved to be an important tool to characterize and identify the new compounds formed, even when at low concentrations.

Thus, in vitro biotransformation experiments using rat liver microsomes proved to be promising for initial biotransformation studies of azo molecules with a high number of nitro groups or substituted amines.

Based on the theoretical results, all dye species presented reactivity when docked in the DNA crystallographic structure; however, Disperse Red 73 showed a higher reactivity in relation to the other dyes, thus suggesting a higher mutagenic potential. This trend was also confirmed with the reaction mechanism calculations. The metabolites also formed a stable complex with DNA. From NBO analyses, the cyanide group is suggested to assist in the good reactivity of DR 73 towards DNA, and the substituent change in DR 78 and DR $167(\mathrm{CN}$ to $\mathrm{Cl}$ ) is suggested to influence the electronic density over the other groups (azo and nitro).

\section{Acknowledgements}

The authors are grateful for the financial support from CNPq (465571/2014-0; 142379/2014-0), CAPES, FAPEMIG (PPM-00883115) and FAPESP (2008/10449-7, 2015/18109-4 and 2014/50945-4).

\section{Appendix A. Supplementary data}

Supplementary data to this article can be found online at https://doi. $\operatorname{org} / 10.1016 /$ j.scitotenv.2017.08.271.

\section{References}

Bafana, A., Devi, S.S., Chakrabarti, T., 2011. Azo dyes: past, present and the future. Environ. Rev. 19:350-371. https://doi.org/10.1139/a11-018.

Banat, I.M., Nigam, P., Singh, D., Marchant, R., 1996. Microbial decolorization of textiledyecontaining effluents: a review. Bioresour. Technol. 58:217-227. https://doi.org/ 10.1016/S0960-8524(96)00113-7.

Beland, F.A., Kadlubar, F.F., 1990. Metabolic activation and DNA adducts of aromatic amines and nitroaromatic hydrocarbons. In: Cooper, C.S., Grover, P.L. (Eds.), Chemical Carcinogenesis and Mutagenesis I. Springer, Berlin Heidelberg, Berlin, Heidelberg: pp. 267-325 https://doi.org/10.1007/978-3-642-74775-5_8.

Belaz, K.R.A., Oliveira, R.V., 2013. HPLC-fluorescence determination of EROD activity in Wistar rat liver microsomes obtained by two different extraction procedures. Curr. Pharm. Anal. 9:43-53. https://doi.org/10.2174/1573412911309010007.

Bernstein, L., Kaldor, J., McCann, J., Pike, M.C., 1982. An empirical approach to the statistical analysis of mutagenesis data from the Salmonella test. Mutat. Res. Mutagen. Relat. Subj. 97:267-281. https://doi.org/10.1016/0165-1161(82)90026-7.

Besler, B.H., Merz, K.M., Kollman, P.A., 1990. Atomic charges derived from semiempirical methods. J. Comput. Chem. 11:431-439. https://doi.org/10.1002/jcc.540110404.

Bradford, M.M., 1976. A rapid and sensitive method for the quantitation of microgram quantities of protein utilizing the principle of protein-dye binding. Anal. Biochem. 72:248-254. https://doi.org/10.1016/0003-2697(76)90527-3.

Brandon, E.F., Raap, C., Meijerman, I., Beijnen, J.H., Schellens, J.H., 2003. An update on in vitro test methods in human hepatic drug biotransformation research: pros and cons. Toxicol. Appl. Pharmacol. 189:233-246. https://doi.org/10.1016/S0041-008X(03)00128-5.

Chequer, F.M.D., Junqueira, D., Oliveira, D.P., 2011. Azo dyes and their metabolites: does the discharge of the azo dye into water bodies represent human and ecological risks? Advances in Treating Textile Effluent. InTech:pp. 520-522 https://doi.org/ $10.5772 / 19872$

Chung, K.T., 1983. The significance of azo-reduction in the mutagenesis and carcinogenesis of azo dyes. Mutat. Res. Genet. Toxicol. 114:269-281. https://doi.org/10.1016/ 0165-1110(83)90035-0.

Chung, K.T., Cerniglia, C.E., 1992. Mutagenicity of azo dyes: structure-activity relationships. Mutat. Res. Genet. Toxicol. 277:201-220. https://doi.org/10.1016/01651110(92)90044-A.

Claxton, L.D., 1983. The integration of bioassay and physiochemical information for complex mixtures. In: Waters, M.D., Sandhu, S.S., Lewtas, J., Claxton, L., Chernoff, N., Nesnow, S. (Eds.), Short-Term Bioassays in the Analysis of Complex Environmental Mixtures III. Springer US, Boston, MA:pp. 153-162 https://doi.org/10.1007/978-14613-3611-2_10.

Claxton, L.D., Houk, V.S., Warner, J.R., Myers, L.E., Hughes, T.J., 1991. Assessing the use of known mutagens to calibrate the Salmonella typhimurium mutagenicity assay: II. With exogenous activation. Mutat. Res. Mutagen. Relat. Subj. 253:149-159. https:// doi.org/10.1016/0165-1161(91)90128-U. da Cunha, E.E.F., Barbosa, E.F., Oliveira, A.A., Ramalho, T.C., 2010. Molecular modeling of Mycobacterium tuberculosis DNA gyrase and its molecular docking study with gatifloxacin inhibitors. J. Biomol. Struct. Dyn. 27:619-625. https://doi.org/10.1080/ 07391102.2010.10508576.

da Cunha, E.F.F., Ramalho, T.C., Reynolds, R.C., 2008. Binding mode analysis of 2,4 diamino-5-methyl-5-deaza-6-substituted pteridines with Mycobacterium tuberculosis and human dihydrofolate reductases. J. Biomol. Struct. Dyn. 25:377-385. https:// doi.org/10.1080/07391102.2008.10507186.

Decloitre, F., Martin, M., Chauveau, J., 1975. Comparative effect of phenobarbital and 3 methyl-cholanthrene on azodye metabolism in rat liver I. In vitro studies on detoxication and activation processes. Chem. Biol. Interact. 10:229-238. https://doi.org/ 10.1016/0009-2797(75)90086-1.

Dipple, A., Michejda, C.J., Weisburger, E.K., 1985. Metabolism of chemical carcinogens. Pharmacol. Ther. 27:265-296. https://doi.org/10.1016/0163-7258(85)90072-5.

Ferraz, E.R.A., Umbuzeiro, G.A., De-Almeida, G., Caloto-Oliveira, A., Chequer, F.M.D., Zanoni, M.V.B., Dorta, D.J., Oliveira, D.P., 2011. Differential toxicity of disperse red 1 and disperse red 13 in the ames test, HepG2 cytotoxicity assay, and Daphnia acute toxicity test. Environ. Toxicol. 26:489-497. https://doi.org/ 10.1002/tox.20576.

Fisher, G.R., Donis, J., Gutierrez, P.L., 1992. Reductive metabolism of diaziquone (AZQ) in the S9 fraction of MCF-7 cells. II. Enhancement of the alkylating activity of AZQ by $\mathrm{NAD}(\mathrm{P}) \mathrm{H}$ : quinone-acceptor oxidoreductase (DT-diaphorase). Biochem. Pharmacol. 44, 1625-1635.

Forgacs, E., Cserháti, T., Oros, G., 2004. Removal of synthetic dyes from wastewaters: a review. Environ. Int. 30:953-971. https://doi.org/10.1016/j.envint.2004.02.001.

Foster, J.P., Weinhold, F., 1980. Natural hybrid orbitals. J. Am. Chem. Soc. 102:7211-7218 https://doi.org/10.1021/ja00544a007.

Gomare, S.S., Jadhav, J.P., Govindwar, S.P., 2008. Degradation of sulfonated azo dyes by the purified lignin peroxidase from Brevibacillus laterosporus MTCC 2298. Biotechnol. Bioprocess Eng. 13:136-143. https://doi.org/10.1007/s12257-008-0008-5.

Gustin, D.J., Mattei, P., Kast, P., Wiest, O., Lee, L., Cleland, W.W., Hilvert, D., 1999. Heavy atom isotope effects reveal a highly polarized transition state for chorismate mutase. J. Am. Chem. Soc. 121:1756-1757. https://doi.org/10.1021/ja9841759.

Haris, P., Mary, V., Haridas, M., Sudarsanakumar, C., 2015. Energetics, thermodynamics, and molecular recognition of piperine with DNA. J. Chem. Inf. Model. 55: 2644-2656. https://doi.org/10.1021/acs.jcim.5b00514.

Hunger, K., 1994. On the toxicology and metabolism of azo dyes. Chim. Int. J. Chem. 48, 520-522.

International Agency for Research on Cancer, 2002. International agency for research on cancer Iarc monographs on the evaluation of carcinogenic risks to humans. Iarc Monogr. Eval. Carcinog. Risks To Humans 96:390. https://doi.org/10.1002/ food.19940380335.

Issar, U., Kumari, T., Kakkar, R., 2015. Assessment of molecular binding of Hoechst 33258 analogues into DNA using docking and MM/GBSA approach. J. Comput. Sci. 10: 166-177. https://doi.org/10.1016/j.jocs.2015.05.003.

Kleinow, K.M., Melancon, M.J., Lech, J.J., 1987. Biotransformation and induction: implications for toxicity, bioaccumulation and monitoring of environmental xenobiotics in fish. Environ. Health Perspect. 71:105-119. https://doi.org/10.1289/ehp.8771105.

Kolekar, Y.M., Kodam, K.M., 2012. Decolorization of textile dyes by Alishewanella sp KMK6. Appl. Microbiol. Biotechnol. 95:521-529. https://doi.org/10.1007/s00253011-3698-0.

Lercher, L., McDonough, M.A., El-Sagheer, A.H., Thalhammer, A., Kriaucionis, S., Brown, T., Schofield, C.J., 2014. Structural insights into how 5-hydroxymethylation influences transcription factor binding. Chem. Commun. 50:1794-1796. https://doi.org/ 10.1039/C3CC48151D.

Levine, W.G., 1985. Studies on microsomal azoreduction: N,N-dimethyl-4aminoazobenzene (DAB) and its derivatives. Biochem. Pharmacol. 34:3259-3264. https://doi.org/10.1016/0006-2952(85)90343-0.

Livingstone, D., 1998. The fate of organic xenobiotics in aquatic ecosystems: quantitative and qualitative differences in biotransformation by invertebrates and fish. Comp. Biochem. Physiol. Part A Mol. Integr. Physiol. 120:43-49. https://doi.org/10.1016/ S1095-6433(98)10008-9.

Luczak, M.W., Jagodzinski, P.P., 2006. The role of DNA methylation in cancer development Folia Histochem. Cytobiol. 44, 143-154.

Maron, D.M., Ames, B.N., 1983. Revised methods for the Salmonella mutagenicity test Mutat. Res. Mutagen. Relat. Subj. 113:173-215. https://doi.org/10.1016/01651161(83)90010-9.

Martin, C.N., Kennelly, J.C., 1981. Rat liver microsomal azoreductase activity on four azo dyes derived from benzidine, 3,3'-dimethoxybenzidine or 3,3'-dimethoxybenzidine. Carcinogenesis 2:307-312. https://doi.org/10.1093/carcin/2.4.307.

Matsuo, A.Y.O., Gallagher, E.P., Trute, M., Stapleton, P.L., Levado, R., Schlenk, D., 2008. Characterization of Phase I biotransformation enzymes in coho salmon (Oncorhynchus kisutch). Comp. Biochem. Physiol. Part C Toxicol. Pharmacol. 147: 78-84. https://doi.org/10.1016/j.cbpc.2007.08.001.

Mitra, D., Kar, M., Pal, R., Basak, A., 2007. Synthesis and reactivity of azobenzene-based bispropargyl sulfones: interesting comparison between cyclic and acyclic systems. Bioorg. Med. Chem. Lett. 17:4514-4517. https://doi.org/10.1016/j.bmcl.2007.06.001.

Morgon, N.H., Coutinho, K., 2007. Métodos de Química Teórica e Modelagem Molecular. Editora Livraria da Física, São Paulo.

Mortelmans, K., Zeiger, E., 2000. The ames Salmonella/microsome mutagenicity assay. Mutat. Res. Mol. Mech. Mutagen. 455:29-60. https://doi.org/10.1016/S00275107(00)00064-6.

Novotný, Č., Dias, N., Kapanen, A., Malachová, K., Vándrovcová, M., Itävaara, M., Lima, N., 2006. Comparative use of bacterial, algal and protozoan tests to study toxicity of azoand anthraquinone dyes. Chemosphere 63:1436-1442. https://doi.org/10.1016/ j.chemosphere.2005.10.002. 
Ogugbue, C.J., Sawidis, T., 2011. Bioremediation and detoxification of synthetic wastewater containing triarylmethane dyes by Aeromonas hydrophila isolated from industrial effluent. Biotechnol. Res. Int. 2011:967925. https://doi.org/10.4061/2011/967925.

Oliveira, D.P., Carneiro, P.A., Sakagami, M.K., Zanoni, M.V.B., Umbuzeiro, G.A., 2007. Chemical characterization of a dye processing plant effluent-identification of the mutagenic components. Mutat. Res. Toxicol. Environ. Mutagen. 626:135-142. https:// doi.org/10.1016/j.mrgentox.2006.09.008.

Osugi, M.E., Rajeshwar, K., Ferraz, E.R.A., de Oliveira, D.P., Araújo, Â.R. Zanoni, MV.B. 2009. Comparison of oxidation efficiency of disperse dyes by chemical and photoelectrocatalytic chlorination and removal of mutagenic activity. Electrochim. Acta 54:2086-2093. https://doi.org/10.1016/j.electacta.2008.07.015.

Pagano, D.A., Zeiger, E., 1992. Conditions for detecting the mutagenicity of divalent metals in Salmonella typhimurium. Environ. Mol. Mutagen. 19:139-146. https://doi.org/ 10.1002/em.2850190208.

Prival, M.J., Davis, V.M., Peiperl, M.D., Bell, S.J. 1988. Evaluation of azo food dyes for mutagenicity and inhibition of mutagenicity by methods using Salmonella typhimurium. Mutat. Res. Toxicol. 206:247-259. https://doi.org/10.1016/0165-1218(88)90168-1.

Rehn, L., 1985. Blasengeschwülste bei Fuchsin-Arbeitern. Arch. Klin. Chir. 50, 588-600.

Ryde, U., 2016. QM/MM calculations on proteins. Methods in Enzymology. United States: pp. 119-158 https://doi.org/10.1016/bs.mie.2016.05.014.

Saratale, R.G., Saratale, G.D., Chang, J.S., Govindwar, S.P., 2011. Bacterial decolorization and degradation of azo dyes: a review. J. Taiwan Inst. Chem. Eng. 42:138-157. https:// doi.org/10.1016/j.jtice.2010.06.006.

Senn, H.M., Thiel, W., 2009. QM/MM methods for biomolecular systems. Angew. Chem. Int. Ed. Eng. 48:1198-1229. https://doi.org/10.1002/anie.200802019.

Silva, T.C., de Almeida, K.J., dos Santos Pires, M., de Castro, A.A., Gonçalves, M.A., da Cunha, E.F.F., Ramalho, T.C., 2017. Theoretical structural and electronic analyses with emphasis on the reactivity of iron oxide prototypes in methane $\mathrm{C}-\mathrm{H}$ bond activation. React. Kinet. Mech. Catal. 120:195-208. https://doi.org/10.1007/s11144-016-1103-9.
Singh, U.C., Kollman, P.A., 1984. An approach to computing electrostatic charges for molecules. J. Comput. Chem. 5:129-145. https://doi.org/10.1002/jcc.540050204.

Sost, D., Amrhein, N., 1990. Substitution of Gly-96 to Ala in the 5-enolpyruvylshikimate 3phosphate synthase of Klebsiella pneumoniae results in a greatly reduced affinity for the herbicide glyphosate. Arch. Biochem. Biophys. 282:433-436. https://doi.org/ 10.1016/0003-9861(90)90140-T.

Stiborová, M., Asfaw, B., Anzenbacher, P., Lešeticky, L., Hodek, P., 1988. The first identification of the benzenediazonium ion formation from a non-aminoazo dye, 1-phenylazo2-hydroxynaphthalene (Sudan I) by microsomes of rat livers. Cancer Lett. 40: 319-326. https://doi.org/10.1016/0304-3835(88)90091-2.

Umbuzeiro, G.A., Freeman, H., Warren, S.H., Kummrow, F., Claxton, L.D., 2005a. Mutagenicity evaluation of the commercial product CI disperse blue 291 using different protocols of the Salmonella assay. Food Chem. Toxicol. 43:49-56. https://doi.org/ 10.1016/j.fct.2004.08.011.

Umbuzeiro, G.A., Freeman, H.S., Warren, S.H de Oliveira, D.P., Terao, Y., Watanabe, T. Claxton, L.D., 2005b. The contribution of azo dyes to the mutagenic activity of the Cristais River. Chemosphere 60:55-64. https://doi.org/10.1016/ j.chemosphere.2004.11.100.

Vineis, P., Pirastu, R., 1997. Aromatic amines and cancer. Cancer Causes Control 8: 346-355. https://doi.org/10.1023/A:1018453104303.

Zanoni, T.B., Lizier, T.M., Assis, M. das D., Zanoni, M.V.B., de Oliveira, D.P., 2013. CYP-450 isoenzymes catalyze the generation of hazardous aromatic amines after reaction with the azo dye Sudan III. Food Chem. Toxicol. 57:217-226. https://doi.org/ 10.1016/j.fct.2013.03.035.

Zbaida, S., Levine, W.G., 1990. Characteristics of two classes of azo dye reductase activity associated with rat liver microsomal cytochrome P450. Biochem. Pharmacol. 40: 2415-2423. https://doi.org/10.1016/0006-2952(90)90081-U. 